\title{
Injury Risk in Behind Armor Blunt Thoracic Trauma
}

\author{
Cameron R. Bass \\ Robert S. Salzar \\ Scott R. Lucas \\ Center for Applied Biomechanics, University of Virginia, Charlottesville, USA
}

Martin Davis

University of Pennsylvania, Philadelphia, USA

Lucy Donnellan

Duke University, Durham, NC, USA

Benny Folk

Anteon Corporation, Washington, DC, USA

Ellory Sanderson

U.S. Army Aberdeen Test Center, Aberdeen, MD, USA

\section{Stanley Waclawik}

\section{U.S. Army Natick Soldier Center, Natick, MA, USA}

First responders and military personnel are particularly susceptible to behind armor blunt thoracic trauma in occupational scenarios. The objective of this study was to develop an armored thorax injury risk criterion for short duration ballistic impacts. 9 cadavers and 2 anthropomorphic test dummies (AUSMAN and NIJ 0101.04 surrogate) were tested over a range of velocities encompassing low severity impacts, medium severity impacts, and high severity impacts based upon risk of sternal fracture. Thoracic injuries ranged from minor skin abrasions (abbreviated injury scale [AIS] 1) to severe sternal fractures (AIS 3+) and were well correlated with impact velocity and bone mineral density. 8 male cadavers were used in the injury risk criterion development. A $50 \%$ risk of AIS 3+ injury corresponded to a peak impact force of 24,900 $\pm 1,400 \mathrm{~N}$. The AUSMAN impact force correlated strongly with impact velocity. Recommendations to improve the biofidelity of the AUSMAN include implementing more realistic viscera and decreasing the skin thickness.

$$
\text { blunt trauma thorax armor ballistic }
$$

The authors gratefully acknowledge support from the U.S. Army Natick Soldier Center, Defence R\&D Canada - Valcartier and the U.S. Army Aberdeen Test Center.

Correspondence and requests for offprints should be sent to Scott R. Lucas, 1011 Linden Ave, Charlottesville, VA 22902, USA. Email: <slucas@ virginia.edu>. 


\section{INTRODUCTION}

Traditionally, steel helmets and body armor have been used to stop or blunt penetration of ballistic projectiles, bullets, or shrapnel into the human body. However, the introduction of modern high impact strength, deformable materials into helmets and body armor for this ballistic impact protection has increased the potential for significant backface deformation under ballistic impact. For most helmet and body armor systems there is limited space available for this backface deformation, thus, systems that suffer no penetration may have a substantial risk of producing severe head or thorax injury from blunt backface trauma. Further, the desire to use even lighter weight head or thorax protection with greater ballistic penetration resistance may lead to increased risk of backface impact injuries. These injuries are often termed Behind Armor Blunt Trauma (BABT). First responders and military personal are susceptible to BABT injuries in occupational scenarios. It is essential to investigate BABT injury patterns and BABT injury thresholds to develop optimal protective helmets and body armor.

There exist no generally accepted injury criteria for thoracic BABT. Current assessment tools for soft body armor assume a displacement mechanism as the source of injury in subjects [1]. In contrast, a number of experiments have found a "twin peaks" phenomenon [2] in behind armor visceral pressure in animals or surrogates. These peaks include a first, sharp, pressure peak (20-90 MPa) of short duration ( $200 \mu \mathrm{s})$, and a second, longer, pressure peak (1-8 MPa, 500$1000 \mu \mathrm{s})$. The first peak is presumably associated with an impedance mismatch between the rear face of the body armor and the thorax, and the second peak is associated with large local bulk displacements of the thorax. An analysis of the strain energy associated with each peak suggests that the first peak has an order of magnitude more energy than the second peak.

The basis for an injury risk assessment for BABT is a biomechanical injury risk model. There are three techniques for producing such injury risk models. These include the use of cadaveric subjects, animal subjects, and epidemiological investigations of injuries. Each technique has its strengths and weaknesses. Cadaveric subjects have accurate anatomy, but lack living physiology. Animal subjects usually possess physiology but lack similar anatomy. Epidemiological studies include both human anatomy and human physiology, but there is often limited knowledge of the conditions under which the incidents occurred.

Cadaver testing is necessary for evaluation of injuries to human anatomical features. These may be associated with physiological results from animal experiments; however, there are substantial differences between the anatomy of porcine livestock and humans, especially in the mediastinal region. There is a very limited number of existing cadaver experiments for hard body armor with ballistic impact. These include investigations by Mirzeabassov, Belov, Tyurin, et al. [3] and others. The results of Mirzeabassov, Belov, Tyurin, et al. have been correlated with animal and human epidemiological results using Soviet body armor. Both test series include mediastinal impacts with $7.62-\mathrm{mm}$ test rounds. There are, however, no reported correlations of mechanical sensor data with resulting BABT injuries that would be useful for development of a test methodology.

There are numerous studies of animals with hard body armor BABT from 5.56-, 7.62-, and $12.7-\mathrm{mm}$ test rounds. Representative porcine studies include experiments from a multinational group termed the NATO BABT Oksbol trials comprised of DGA (France) [4] and Anter (Russia) [3]. The injury criterion developed from the Oksbol trials was not based on mechanical sensor data, and the corresponding animal tests did not produce sufficient differentiation between injuries. The series of tests performed by the DGA included mediastinal and lateral impacts, while recording physiological and engineering sensor data. However, the series did not result in an injury criterion suitable for use in mediastinal impacts behind hard body armor. The Anter series included human cadaver, animal, and epidemiological data to produce an injury criterion for specific body 
armors used by the Soviet Army in Afghanistan. This investigation, however, did not result in an injury criterion based on mechanical data. Epidemiology of BABT incidents with hard body armor is very limited. Available data includes the WDMET database from the U.S. Army [5] based on Vietnam era battle casualties. This database, however, does not include injuries from personnel wearing modern hard body armors. The most complete and organized collection of BABT injuries behind hard body armor was reported by Mirzeabassov, Belov, Tyurin, et al. [3]. These were obtained from medical personnel attached to Soviet forces in Afghanistan. The medical and physical data were taken from 17 subjects wearing several different designs of body armor including titanium plates of 1.25and $6.5-\mathrm{mm}$ thickness. The data also includes estimated ranges, weapon, bullet energy, and medical outcome. The data may be useful for providing bounds on injuries using rounds of energies to $3 \mathrm{~kJ}$. However, the specific design of Soviet body armor limits the direct applicability to an injury model using modern ceramic or ultra high molecular weight polyethylene (UHMWPE) plates.

This study focuses on BABT for hard body armor against rifle threats, principally the 7.62-mm NATO ball round. Injuries that involve backface deformation of composite hard body armor into the anterior thorax (mediastinum) are investigated using nine cadaveric subjects. In addition, two human surrogate (dummy) models are evaluated for biofidelity. This study contributes data from a series of cadaver tests and an injury criterion based on projectile impact force. Consistent sternal fractures in the cadavers suggest that the impact force is a contributing parameter to injury. If more rib fractures occurred, the viscous criterion (VC) [6] or blunt criterion (BC) [7] would be more appropriate, where the energy transferred to the body must be considered in injury assessment. A limitation to $\mathrm{VC}$ and $\mathrm{BC}$ in this application is their uncertain accuracy at ballistic rates.

\section{METHODS}

Cadaveric specimen tests involving BABT were performed using a 7.62-mm test round (7.62 ball round $-9.72 \mathrm{~g}$ ) and a hard body armor selected for high deformation with low probability of penetration for round velocities of approximately $670-800 \mathrm{~m} / \mathrm{s}$. These velocities were selected from previous studies on ballistic helmet testing to provide low, moderate, and high risk of thoracic injury based on the published values for human bone strength and the unpublished values for viscoelastic thoracic response. The high velocity was selected using existing tolerances as the velocity most likely to cause sternal fracture. The moderate velocity was selected as the velocity likely to cause sternal fractures in $50 \%$ of the subjects. The low velocity was selected as the velocity unlikely to cause sternal fracture in test subjects. The test matrix for the nine cadaver tests is included in Table 1.

TABLE 1. Test Matrix for Ultra High Molecular Weight Polyethylene (UHMWPE) Body Armor and $7.62 \mathrm{~mm}$ Rounds

\begin{tabular}{lcccc}
\hline Test & Velocity $(\mathbf{m} / \mathbf{s})$ & Specimen & Gender & Age \\
\hline BABT_2_1 & 790 & FRM-153 & M & 65 \\
BABT_2_2 & 791 & FRM-158 & M & 65 \\
BABT_2_3 & 762 & FRM-141 & M & 65 \\
BABT_2_4 & 761 & FRM-152 & M & 70 \\
BABT_2_5 & 730 & FRM-142 & M & 45 \\
BABT_2_6 & 700 & FRM-162 & M & 43 \\
BABT_2_7 & 722 & FRM-171 & M & 67 \\
BABT_2_8 & 698 & FRF-180 & F & 70 \\
BABT_2_9 & 668 & FRM-172 & M & 54 \\
\hline
\end{tabular}

Notes. BABT—behind armor blunt trauma. 


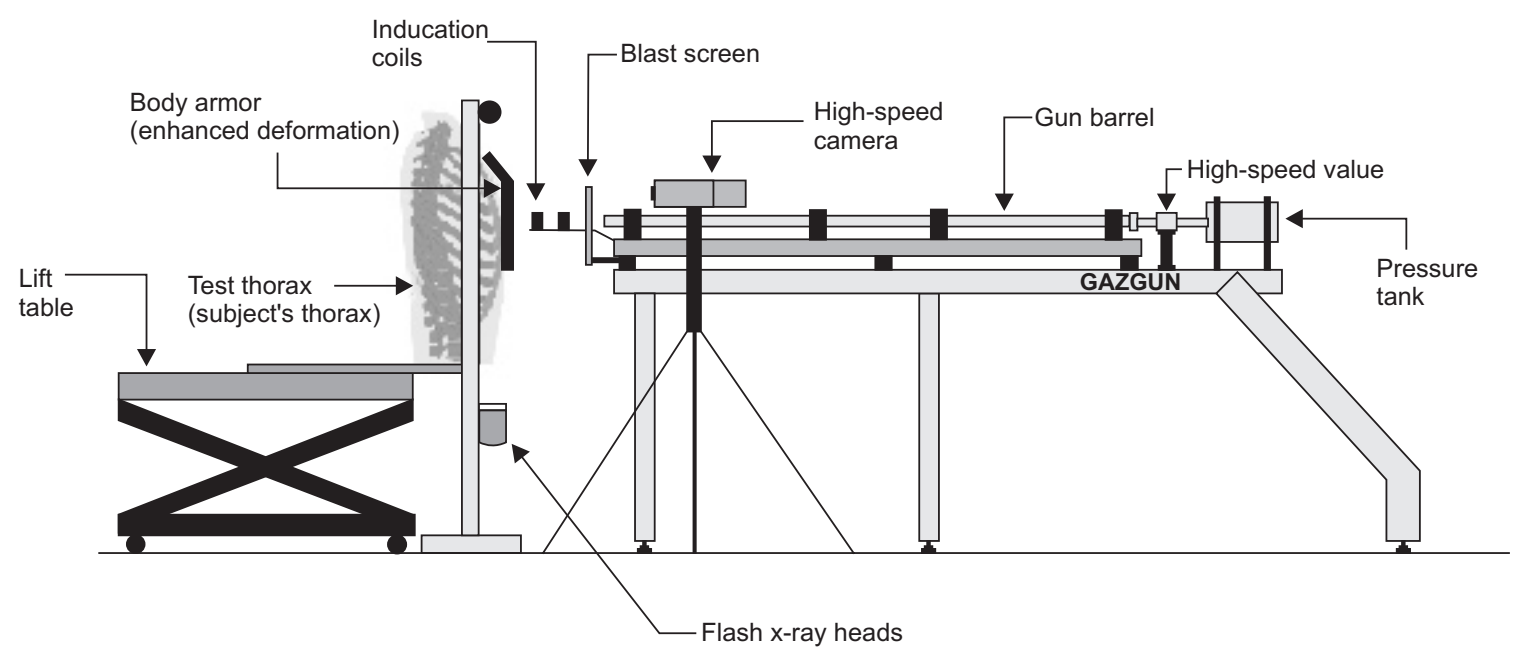

Figure 1. Test fixture schematic.

The primary test component was based on a head support fixture designed and fabricated by the Center for Applied Biomechanics (University of Virginia, USA) as shown in Figure 1. Used in previous ballistic testing, the fixture was designed for use with cadaveric subjects. A sabot was used with a smooth bore barrel (sabot mass $=1 \mathrm{~g}$ ). No bullet instability was seen in the approximately $35-\mathrm{cm}$ flight to impact. The incoming round velocity was measured using an inductive technique and video analysis. The nominal impact location was the center of the sternum as shown in Figure 2, and the body armor was fitted securely to the test subjects. The specimen pulmonary system and cardiovascular system were pressurized to mean physiological values ( $\sim 1 \mathrm{psi}[6.9 \mathrm{kPa}$ ] for the pulmonary system and $\sim 100 \mathrm{mmHg}$ [13 $\mathrm{kPa}$ ] for the cardiovascular

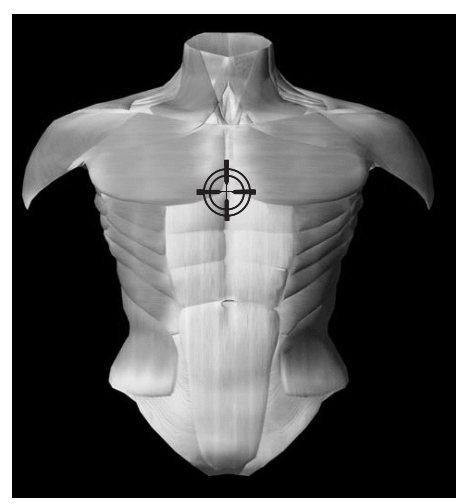

Figure 2. Impact location: mid-sternum, midsagittal plane (marked with a bull's-eye). system) to provide a realistic specimen thoracic response.

A single type of body armor was selected for cadaver tests (Figure 3). The UHMWPE body armor was chosen to provide large deformations without penetration. The curvature of the body armor about the superior-inferior axis is similar to that of a human thorax. Two shots, one in the superior half of the armor and one in the inferior half of the armor, were performed in each plate of body armor.

The tests were recorded using a Phantom V.5 (Vision Research, USA) high-speed digital video imager (up to $60,000 \mathrm{fps}$ ) at a right angle to the shot line. High-speed cineradiography was used to study the deformation of the body armor into the thorax under ballistic impact. The system was comprised of up to four $150 \mathrm{kVp}$ flash $\mathrm{x}$ ray heads aimed at the armor/body into two orthogonal phosphor storage media. X-ray flash pulse widths were approximately $70 \mathrm{~ns}$. The trigger used by the $\mathrm{x}$-ray system was a surface mounted trigger spanning the impact site which was broken by the impact of the bullet. The flash $x$-ray images allowed analysis of the backface deformation of the body armor into the specimen.

This study used cadaveric specimens for a human injury model that were to be compared with existing dummy tests to provide an objective test methodology; therefore, the instrumentation used in the cadaveric specimen was matched as closely as possible to that used in the previous 


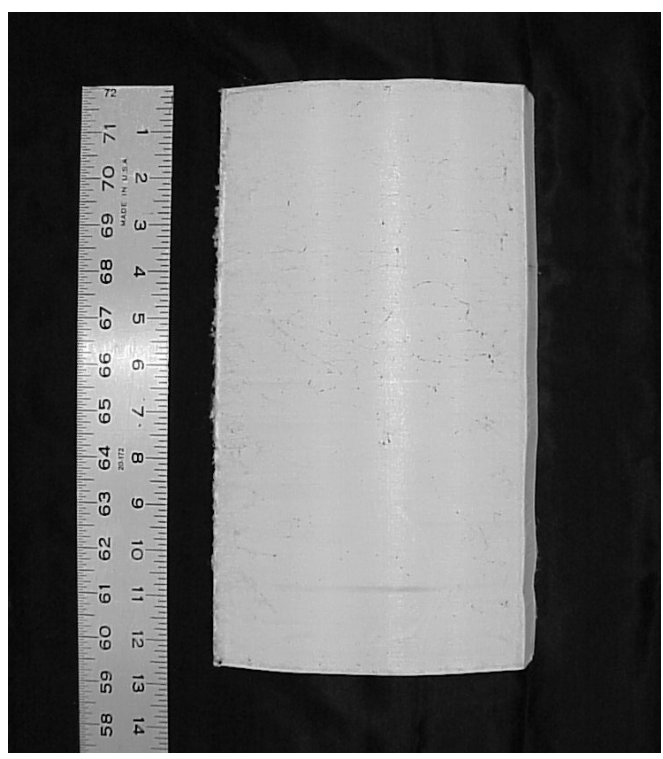

(a) Front

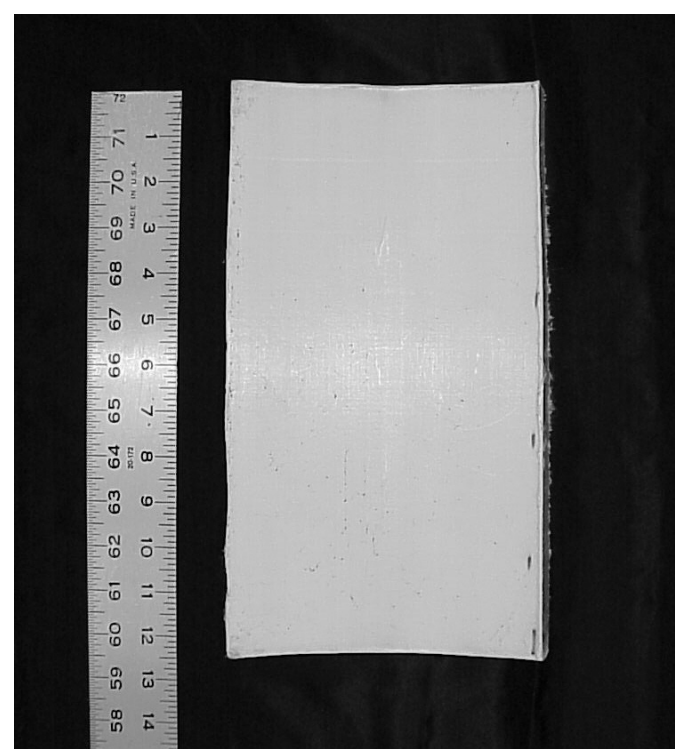

(b) Rear

Figure 3. Samples of ultra high molecular weight polyethylene (UHMWPE) body armor used in this test series. Notes. Each test panel measured $6 \times 317.5 \mathrm{~mm}$. Panels had a slight concavity allowing for a better fit to the thorax.

dummy test series. Instrumentation for the direct impact tests was selected with three primary objectives: the measurement of sternum contact force; the measurement of sternum accelerations; and the determination of global forces and motions. Instrumentation included sternal accelerometers mounted to the upper and lower sternum and thin film stress/strain sensors attached to the sternum to measure sternal force at the impact site. As the impact force sensor is also sensitive to bending under impact, the collocated strain gauge may be used to determine the portion of the impact force signal that can be attributed to bending and the portion that can be attributed to impact force. In addition, fiber optic pressure sensors were used to measure local pressure fields behind the impact site, and ultrasonic sensors were used to measure deformations in the thoracic cavity. Pressure transducers were placed in the vascular system to measure systemic pressure. To determine global acceleration response, a sixaxis accelerometer/angular rate sensor array was mounted on the T6 vertebra. Data was sampled at $1 \mathrm{MHz}$ with a $250-\mathrm{kHz}$ anti-alias filter. The initiation of sternal fracture was recorded using an acoustic sensor. After each test, the specimens were examined for gross injury including sternal fractures and rib fractures.

\subsection{Biological Specimens}

Use of biological specimens is governed by the Cadaver Use Review Panel at the University of Virginia, USA. Specimens were selected to be close to a 50th percentile U.S. male population as shown in Table 2. Nine fresh frozen cadaveric thoraxes were used in this study. These specimens averaged about $3 \mathrm{~cm}$ taller than the 50\% U.S. male $(\sim 1,750 \mathrm{~mm})$ and approximately $3 \mathrm{~kg}$ heavier $(\sim 77 \mathrm{~kg})$. The specimen bone mineral density assessed using a histogram technique (QBMap, The IRIS, Inc., USA). Z-scores are performed relative to an age-matched population ( $\mathrm{UCSF}^{1}$ reference population), and $T$-scores are performed relative to a 25 -year-old population (UCSF reference population). $T$-scores below -1.0 indicate osteopenia, while $T$-scores below

\footnotetext{
${ }^{1}$ UCSF is the University of California, San Francisco. The QBMap uses this population within the software to determine Z-scores and $T$-scores.
} 
TABLE 2. Specimen Parameters

\begin{tabular}{|c|c|c|c|c|c|c|c|c|}
\hline Test & Specimen & Gender & Age & $\begin{array}{c}\text { Mass } \\
(\mathrm{kg})\end{array}$ & $\begin{array}{c}\text { Stature } \\
(\mathrm{mm})\end{array}$ & $\begin{array}{c}\text { BMD } \\
\text { (mg/cc) }\end{array}$ & Z-Score & T-Score \\
\hline BABT_2_1 & FRM-153 & $\mathrm{M}$ & 65 & 78 & 1,780 & 205 & 2.6 & 0.6 \\
\hline $\mathrm{BABT}_{-} 2 \_2$ & FRM-158 & $M$ & 65 & 90 & 1,800 & 177 & 2.0 & -0.3 \\
\hline BABT_2_3 & FRM-141 & M & 65 & 78 & 1,780 & 158 & 1.4 & -0.9 \\
\hline BABT_2_4 & FRM-152 & M & 70 & 80 & 1,780 & 160 & 1.8 & -0.9 \\
\hline BABT_2_5 & FRM-142 & M & 45 & 112 & 1,880 & 269 & 3.8 & 2.6 \\
\hline BABT_2_6 & FRM-162 & M & 43 & 114 & 1,880 & 167 & 0.4 & -0.6 \\
\hline BABT_2_7 & FRM-171 & M & 67 & 104 & 1,890 & 142 & 1.0 & -1.4 \\
\hline BABT_2_8 & FRF-180 & $\mathrm{F}$ & 70 & 54 & 1,626 & NA & NA & NA \\
\hline \multirow[t]{3}{*}{ BABT_2_9 } & FRM-172 & M & 54 & 89 & 1,780 & 177 & 1.4 & -0.3 \\
\hline & $M$ & & 60 & 89 & 1,800 & & & \\
\hline & $S D$ & & 10 & 19 & 80 & & & \\
\hline
\end{tabular}

Notes. BMD—bone mineral density, BABT—behind armor blunt trauma, NA—not available; UCSF reference population, young age for $T$-score is 25 years.

-1.5 indicate osteoporosis. The specimens had generally good bone density. Only one specimen was osteopenic with no evidence of osteoporosis. Bone densitometry could not be performed for specimen FRF-180 using the histogram technique owing to a lack of well-defined retrospinal fat deposits.

\subsection{Anthropomorphic Test Devices}

Two dummy surrogates were used in this test series for comparison with the cadaveric results.
The first was the AUSMAN dummy shown in Figure 4. AUSMAN was a reusable mechanical surrogate developed by the Australian Department of Defense - Defense Science and Technology Organization (DSTO) [8]. AUSMAN consists of a metallic skeletal system enveloping a simulated cardiopulmonary system and incorporates flexible costovertebral sections and a realistic spine. The entire thorax is encased in a room temperature vulcanizing (RTV) polymer.
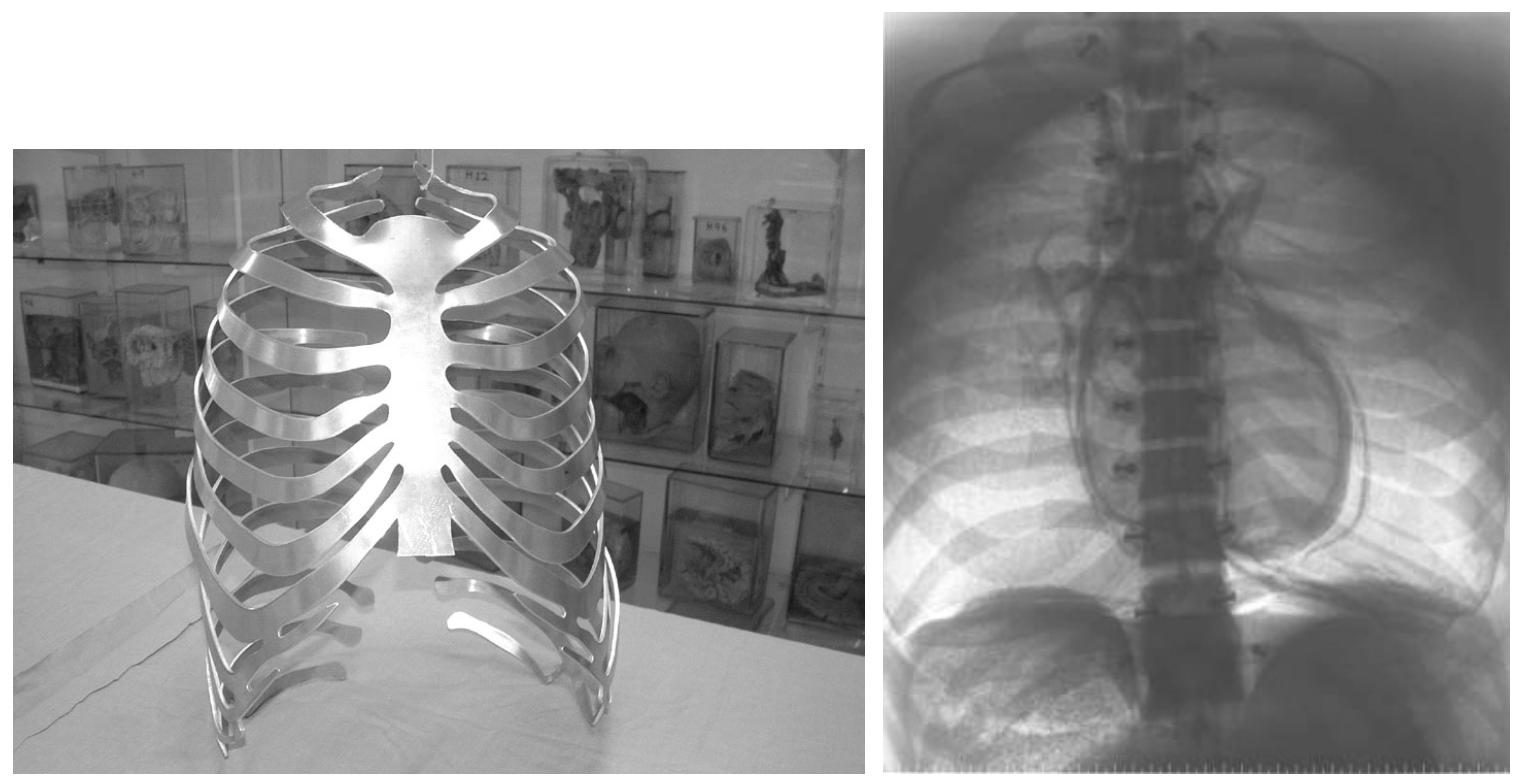

Figure 4. Ribcage and radiograph of AUSMAN surrogate. Notes. AUSMAN-a reusable mechanical surrogate developed by the Australian Department of Defense - Defense Science and Technology Organization (DSTO). 
The second dummy was the surrogate specified by National Institutes of Justice Standard NIJ 0101.04 [9]. The residual deformation of the body armor backface into Roma Plastilina No. 1 (oil based modeling clay) is used as a standard for evaluating the performance of the body armor. Indeed, the body armor compliance program of the NIJ is the oldest of NIJ's commercial testing programs [8]. This standard specifies a 44-mm behind armor deformation threshold into the clay as the pass/fail criterion (Figure 5). The procedure

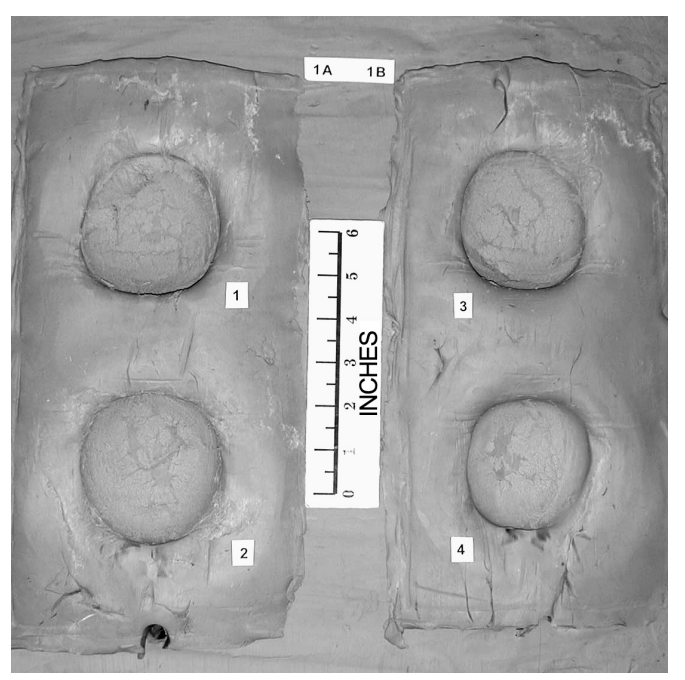

Figure 5. Impact deformations in clay.

for fixturing the clay has been specified in the recent standard, and a calibration test has been improved to increase the repeatability between tests and between test labs. The standard also requires pre- and post-test sequence drop tests. The standard was validated using a correlation with injuries behind soft body armor experienced in ballistic tests on goats [10]. The results were subsequently scaled to humans.

These surrogates are representative of different types of test devices for behind armor blunt trauma. AUSMAN is intended to be a research surrogate for investigation of thoracic deformation under ballistic impact, while the NIJ standard [9] is intended to provide a maximum limit for ballistic backface deformation for production of ballistic protective equipment.

\section{RESULTS}

\subsection{Injuries}

The extent of armor deformation into the thorax is apparent when viewing the body armor with the high-speed dynamic flash $\mathrm{x}$-ray as shown in Figure 6. Generally, the projectile penetrated from $2 / 3$ to $3 / 4$ the thickness of the armor while the armor backface deformed approximately 30 $40 \mathrm{~mm}$ into the subject's thorax.

This deformation often resulted in bony fractures and other injuries; a typical extensive sternal injury from BABT is shown in Figure 7. The primary injuries assessed in this study were the occurrence of sternal or rib fractures, and evidence of vascular damage or bruising. The abbreviated injury scale (AIS) was used to

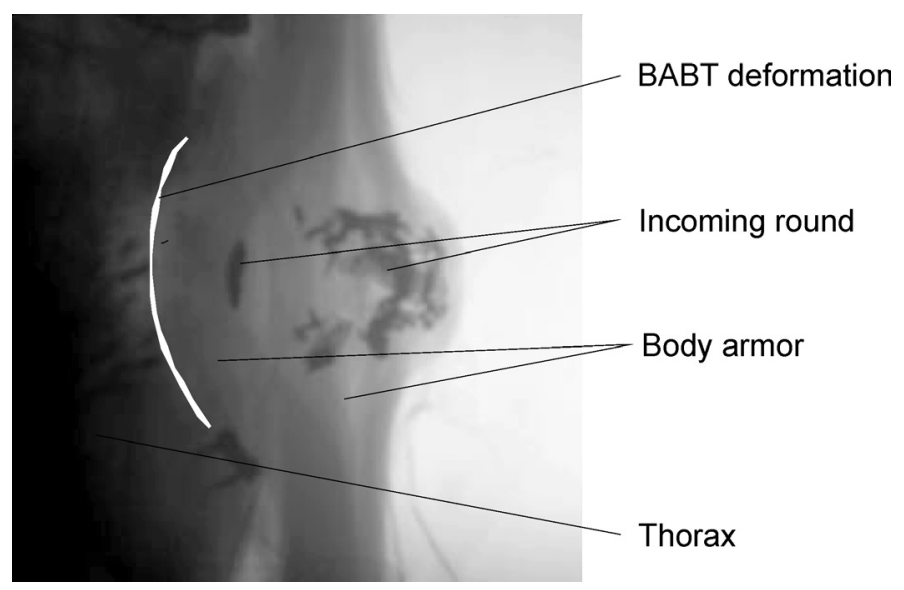

Figure 6. Flash x-ray post-test deformation of the body armor plate. Notes. BABT—behind armor blunt trauma. 


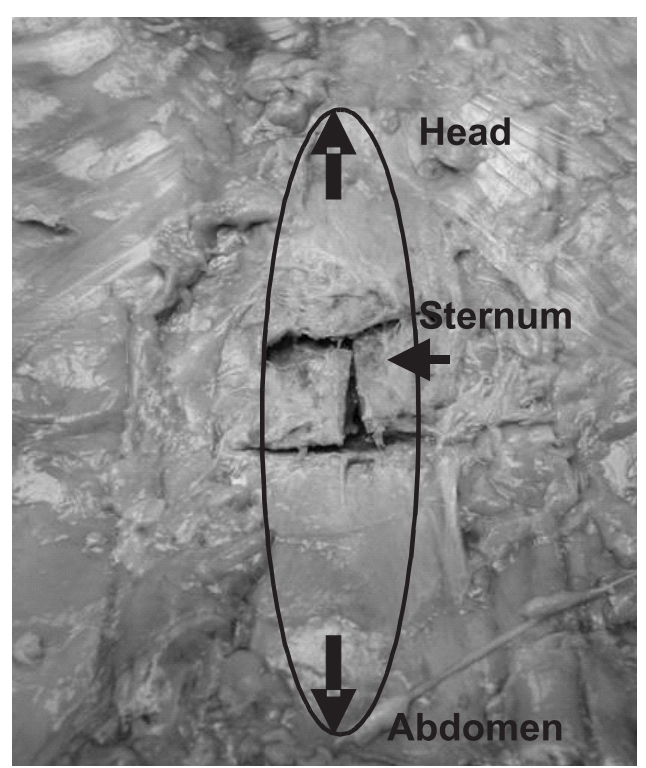

Figure 7. Typical injury (sternal fracture). characterize the injuries. This injury scaling is a threat-to-life scale promulgated by the Association for the Advancement of Automotive Medicine [11]. The injury values in AIS are 0-no injury, 1-minor, 2-moderate, 3-serious, 4-severe, 5-critical, 6-maximum or invariably fatal injury).

The injuries sustained by the specimens in this test are summarized in Table 3 for each biological specimen test. Injuries ranged from minor skin abrasions to severe fractures with abrasive trauma. The injuries generally scaled with both velocity and bone density. The specimens with the lowest bone density generally had the greatest injuries.

TABLE 3. Summary of AIS Scores for Biological Specimen Tests

\begin{tabular}{lccc}
\hline Test & Specimen & Velocity $(\mathrm{m} / \mathbf{s})$ & Max. AIS \\
\hline BABT_CAD_2_1 & FRM-153 & 790 & 1 \\
BABT_CAD_2_2 & FRM-158 & 791 & 2 \\
BABT_CAD_2_3 & FRM-141 & 762 & 4 \\
BABT_CAD_2_4 & FRM-152 & 761 & 3 \\
BABT_CAD_25 & FRM-142 & 730 & 2 \\
BABT_CAD_26 & FRM-162 & 700 & 2 \\
BABT_CAD_2_7 & FRM-171 & 722 & 2 \\
BABT_CAD_2_8 & FRF-180 & 698 & 4 \\
BABT_CAD_29 & FRM-172 & 668 & 1 \\
\hline
\end{tabular}

Notes. BABT—behind armor blunt trauma, AIS—abbreviated injury scale [11]; AIS scores: 0—no injury, 1minor, 2-moderate, 3-serious, 4-severe, 5-critical, 6-maximum.

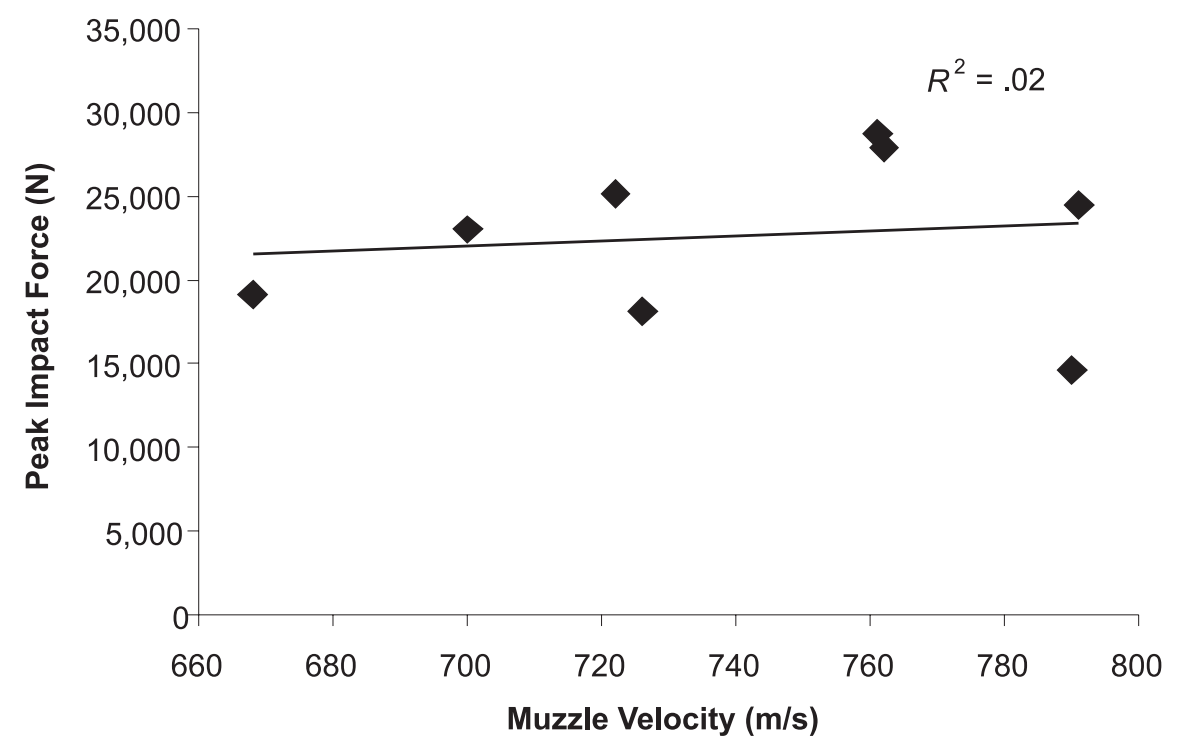

Figure 8. Impact force versus velocity for biological specimens. 


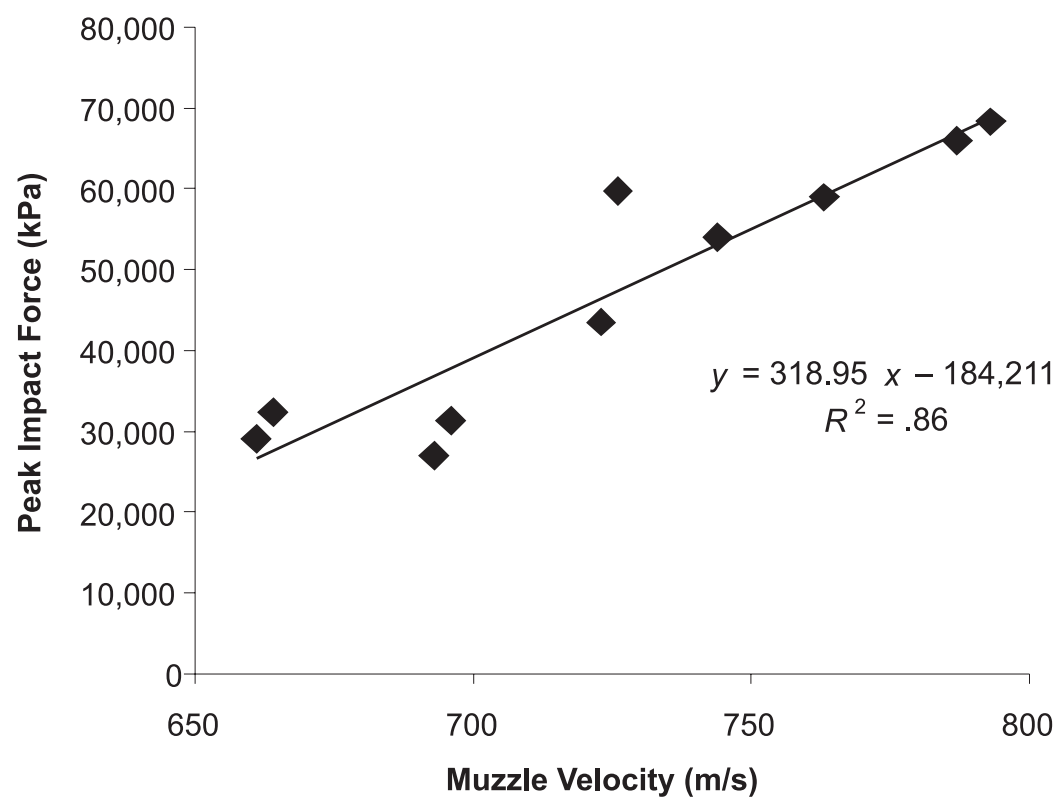

Figure 9. Impact force versus velocity for AUSMAN dummy. Notes. AUSMAN-a reusable mechanical surrogate developed by the Australian Department of Defense - Defense Science and Technology Organization (DSTO).

\subsection{Sensor Data}

Figures 8 and 9 show the impact force relative to velocity for the biological specimens and for AUSMAN, respectively. Owing to the occurrence of fracture in the biological specimens and variations in cadaveric bone strength, the sternal force is not well correlated with velocity since the peak impact force in the specimens selects for the underlying strength of the specimen sternum. However, the impact force is better correlated with velocity for AUSMAN because no failures occur at impact.

To assess the risk of sternal fracture for this hard armor system, a survival analysis was performed using the peak impact force from the biological specimen experiments. Only the eight male specimens were used in the analysis. Assuming a logistic distribution, the risk functions were derived using a parametric survival analysis. The injury risk for a logistic regression is given as

$$
\operatorname{Risk}(F)=\frac{1}{1+\exp \left[\frac{a-F}{b}\right]},
$$

where $F$ is the axial compressive load, and $a$ and $b$ are the coefficients of the logistic distribution. For the creation of the risk function relative to the AIS injury scores, it is assumed that the injury results occur at the peak axial compressive force, and are therefore considered uncensored data. This is justified, as once injury occurs the loading path is destroyed. The injury risk function for peak sternal impact force is shown in Figure 10. For the system tested in this study, $50 \%$ risk of sternal injury, as defined by sternal fracture, is obtained at a peak sternal force of $24,900 \pm 1,400 \mathrm{~N}$.

A series of tests was performed using the NIJ standard [9] at a commercial test laboratory with the hard body armor system used in this test series. The test round was a 7.62 M80 ball projectile. Twenty tests were performed at velocities ranging from $\sim 670$ to $\sim 800 \mathrm{~m} / \mathrm{s}$. The resulting backface deformations showed a very low correlation of deformation with the range of velocities (Figure 11). In contrast, response of the AUSMAN dummy and the biological specimen surrogates over the same velocity range showed a wide range of injury outcomes that generally 


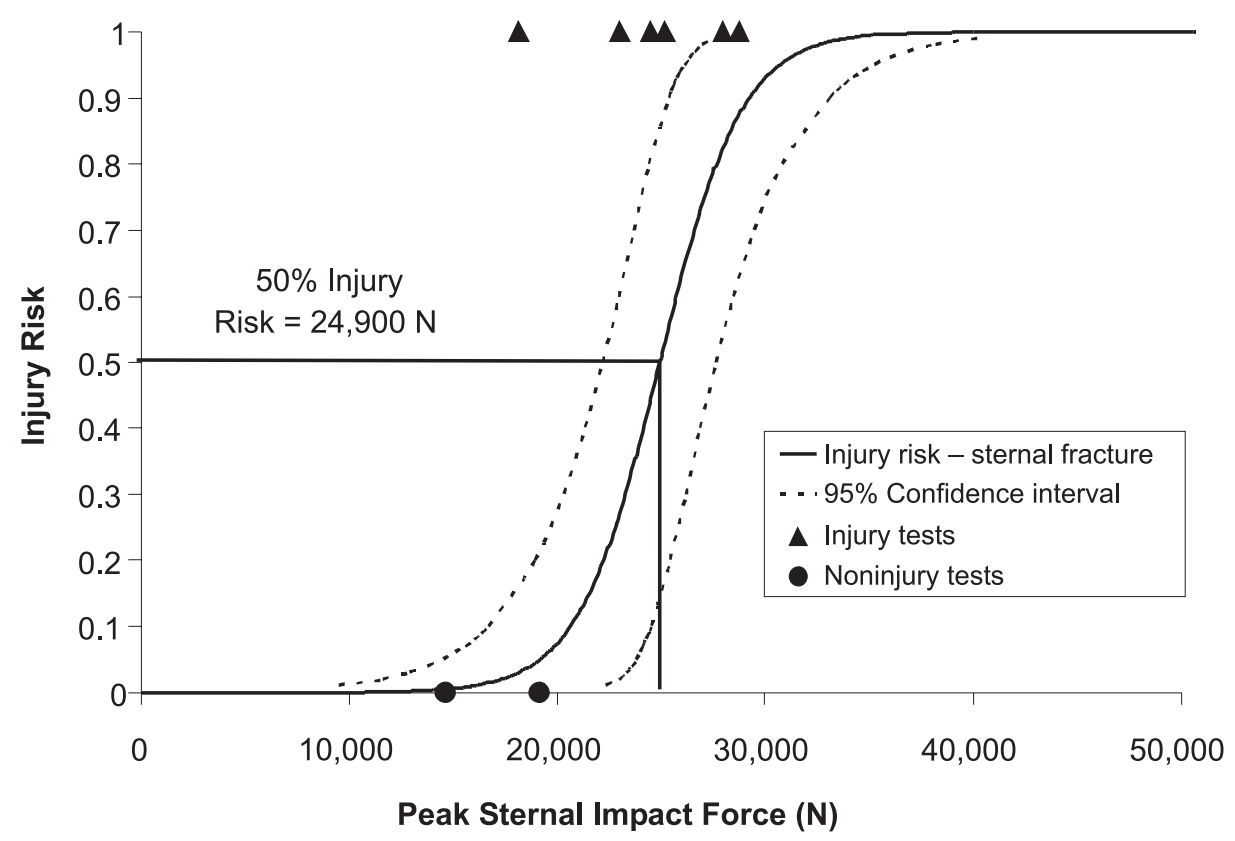

Figure 10. Injury risk function from logistic survival analysis.

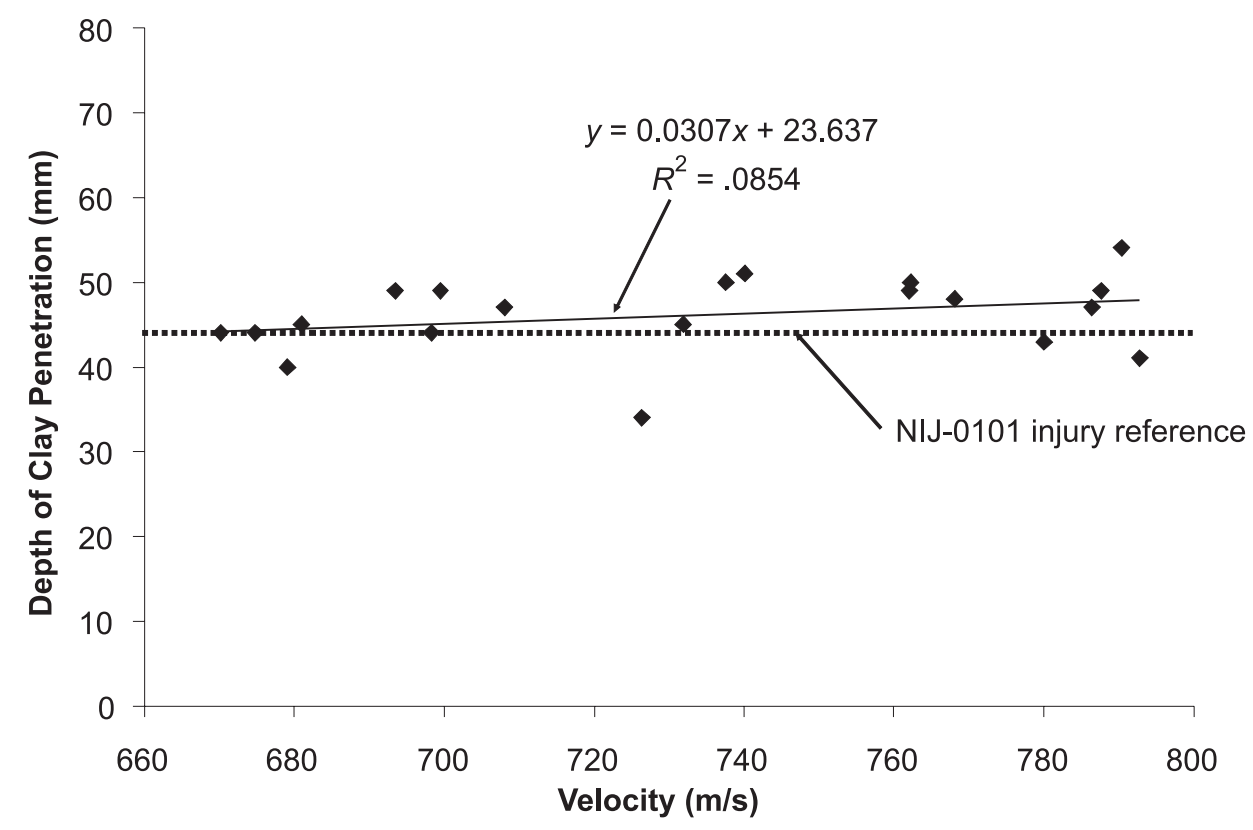

Figure 11. Variation of clay penetration depth with velocity for behind body armor deformation (7.62mm NATO round, ultra high molecular weight polyethylene [UHMWP] body armor). 


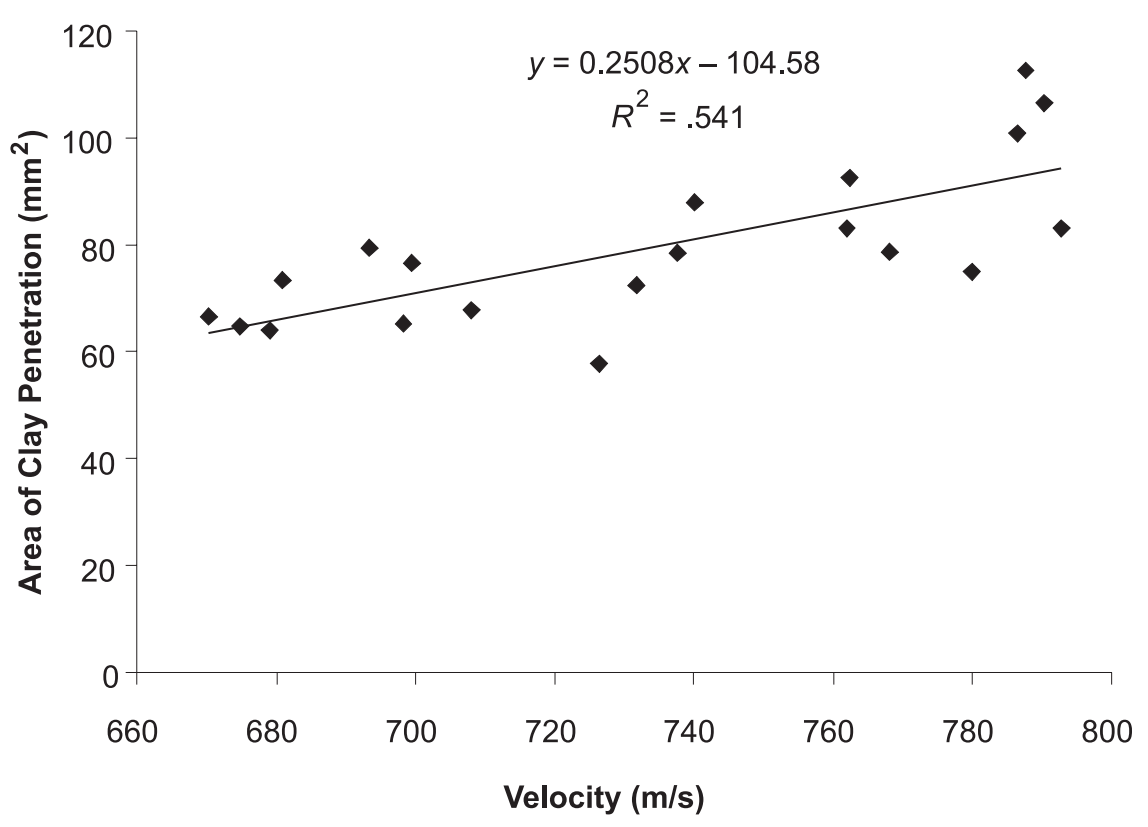

Figure 12. Variation of clay penetration area with velocity for behind body armor deformation (7.62mm NATO round, ultra high molecular weight polyethylene [UHMWPE] body armor).

scaled well with velocity. Measurements of the cross-sectional area or volume of the clay improved the correlation, but the $R^{2}$ value was still lower than .6 (Figure 12).

\section{DISCUSSION}

A comparison of response of AUSMAN dummy and cadaver sternal acceleration is shown in Figure 13. Though the AUSMAN surrogate shows response that generally scales well with impact energy and deformation, the AUSMAN dummy appears to be stiffer than the cadavers from automobile rates through ballistic rates (factor of 3 at automobile impact rates [12]) There are, however, not sufficient cadaver sternal acceleration results to provide a definitive comparison at ballistic rates. So, although it is possible to derive a transfer function between the biological specimens and AUSMAN for the short term elastic response, the preferred approach would be to adjust the properties of the AUSMAN thorax to correct the limited viscoelastic contribution in AUSMAN thorax and substantially greater stiffness compared to cadaveric specimens.
In addition to the AUSMAN dummy, the armor backface performance was evaluated using the NIJ 0101.04 standard [9]. The two dummy surrogates are generally intended for different applications. Though the standard has arguably been very successful, resulting in body armor designs that have saved thousands of military and law enforcement personnel, there are several limitations of this procedure for the design of optimal body armor systems. First, unlike the clay, the human thorax is generally viscoelastic. It is unlikely the response is appropriate for widely varying rates of deformation. In addition, as the methodology was validated using animal surrogates, the test is not likely to be appropriate over wide ranges of deformation. In addition, the standard does not account for the effect of local penetrations (penciling effect). Such a penciling effect may be frequently seen in soft body armor backing [13].

Further, the NIJ 0101.04 evaluation procedure relies on the measurement of the static residual depth of penetration into the clay. Bir [14] performed an analysis of dynamic clay deformation for non-lethal baton rounds. She found that there was no guarantee that the residual deformation was equal to the dynamic deformation. Indeed, individual tests saw as 


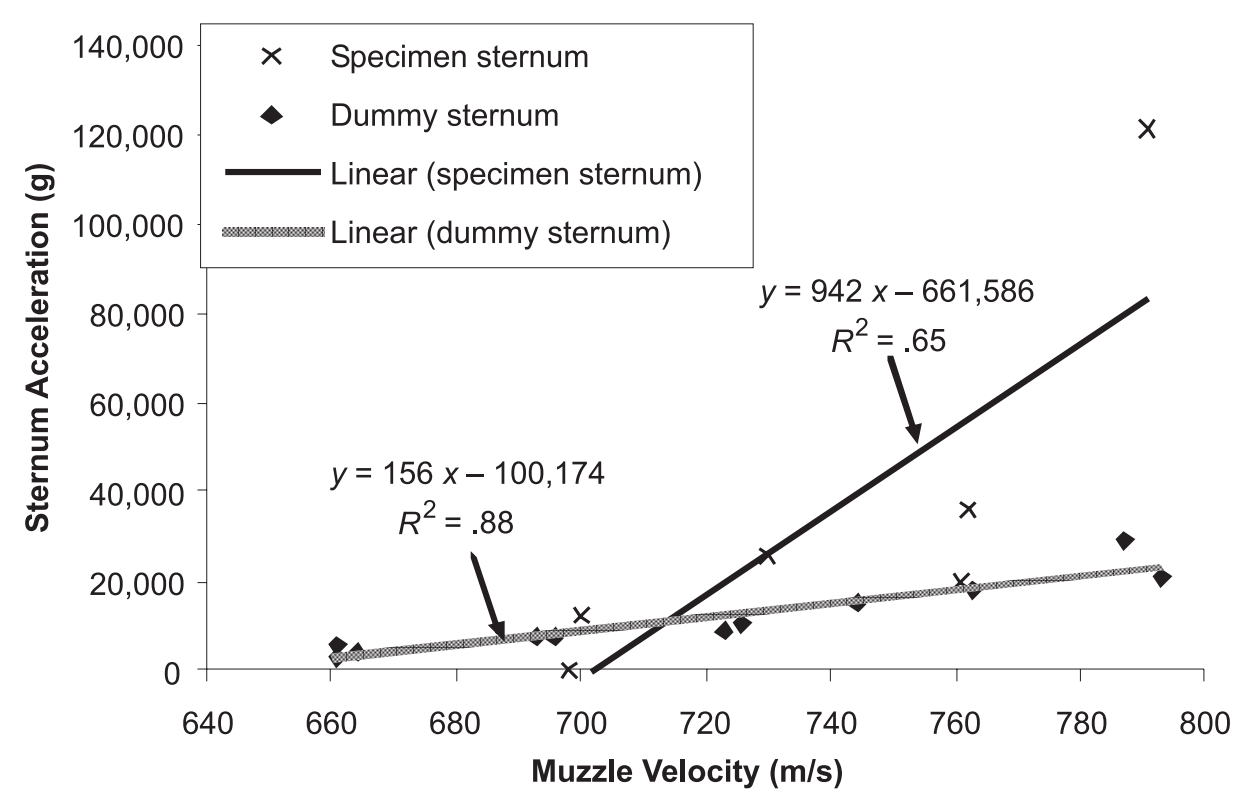

Figure 13. Dummy versus cadaver sternal acceleration.

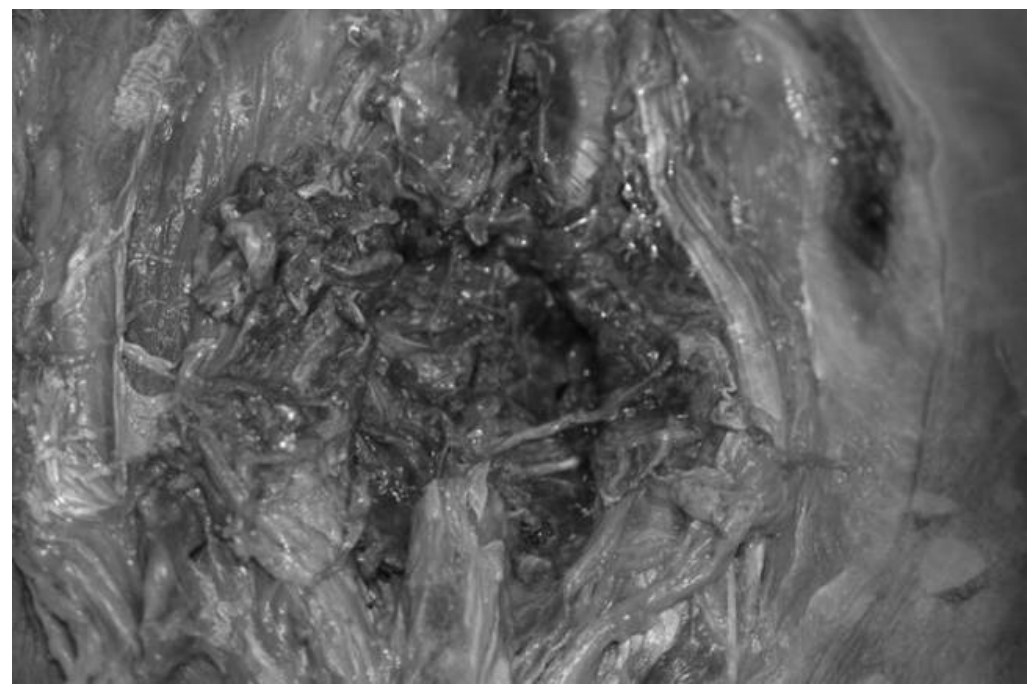

Figure 14. AIS = 5 spinal injury for specimen FRF-180 (ultra high molecular weight polyethylene [UHMWPE] body armor, 7.62-mm test round, velocity = $700 \mathrm{~m} / \mathrm{s}$ ). Notes. AIS-abbreviated injury scale [11]. AIS scores: 0-no injury, 1-minor, 2-moderate, 3-serious, 4-severe, 5-critical, 6-maximum.

much as $20 \%$ greater dynamic deformation than residual quasistatic deformation. In addition, there is no evidence that this dynamic deformation is not rate sensitive and contact-area sensitive.

This study assumed that mediastinal impact was a worst case for thoracic impact. To assess this assumption, a single mid-spinal impact was performed using the same test round and body armor used in this study. The test was performed using specimen FRF-180 with a 7.62-mm round velocity of $700 \mathrm{~m} / \mathrm{s}$. This resulted in a spinal impact under the same conditions as a sternal impact with the same specimen $(700 \mathrm{~m} / \mathrm{s})$. No instrumentation was used in the test. AIS $=5$ injuries received from the spinal backface deformation are shown in Figure 14. They include a laceration between thoracic vertebrae T9 and T12 and disintegration of the associated spinous processes down to the spinal canal. The sternal impact from the same subject resulted in 
injuries with a maximum AIS of 4. This result suggests that further research into spinal impact consequences could be of significant value.

\section{CONCLUSIONS AND RECOMMENDATIONS}

Severe injuries may be caused by non-penetrating projectiles owing to large deformations in the protective body armor. This study developed a biological specimen injury risk function for BABT from sternal impact force measurements. This injury risk function gives a $50 \%$ risk of injury (fracture) at approximately $25,000-\mathrm{N}$ peak sternal force. This injury criterion should be considered in the design of body armor for first responders and military personnel for protection in occupational scenarios.

Further, the study investigated the use of a realistic dummy as a research tool for BABT testing. Several improvements are recommended to improve the biofidelity of the AUSMAN human surrogate. First, the thoracic response in compression is stiffer than that of a human as the AUSMAN has a rigid costocondral junction. Second, the current AUSMAN thorax is almost purely elastic, but the human thorax is viscoelastic, so the implantation of more realistic viscera is recommended. Third, it is recommended that the AUSMAN skin thickness be decreased to more accurately represent human skin. Fourth, internal improvements can also be made to improve biofidelity such as the material properties of the internal organs including the aorta, pleura, and others.

The study determined that for this body armor system, the clay displacement specified in the NIJ standard [9] did not correlate well with test round velocity. This suggests that the clay system may have limitations in assessing the particular body armor system studied. These limitations may be generic as clay does not provide the viscoelastic response typical of human thoraces. One caveat to this conclusion is that the hard armor system tested has no additional components (inner layers of soft ballistic resistant material or anti-trauma decoupling layers) that may serve to alter the response of the clay system.
Finally, mediastinal impact may not be the worst case for behind hard armor impact. Preliminary data from a single specimen with a matched sternal and spinal impact behind the body armor suggests that additional spinal impact research would be of significant value.

\section{REFERENCES}

1. Prather R, Swann C, Hawkins C. Backface signatures of soft body armors and the associated trauma effects (Technical Report No. ARCSL-TR-77-55). Aberdeen Proving Ground, MD, USA: U.S. Army Armament Research and Development Command; 1977.

2. van Bree J, Gotts P. The "twin peaks" of BABT. In: Proceedings from the 5th Personal Armor Systems Symposium. Colchester, UK: International Personal Armour Committee; 2000. p. 357-65.

3. Mirzeabassov $\mathrm{T}$, Belov $\mathrm{D}$, Tyurin $\mathrm{M}$, Klyaus L. Further investigation of modelling for bullet-proof vests. In: Proceedings from the 5th Personal Armor Safety Symposium. Colchester, UK: International Personal Armour Committee; 2000. p. 211-34.

4. Sarron JC, Caillou JP, Destombe C, Lonjon T, Da Cunha J, Vassout P, et al. Review of behind armor blunt trauma since 1999. NATO paper RTO-MP-AVT097, presented at the joint RTO AVT/ HFM Specialists' Meeting on "Equipment for Personal Protection (AVT-097)" and "Personal Protection: Bio-Mechanical Issues and Associated Physio-Pathological Risks (HFM-102)", Koblenz, Germany, 19-23 May 2003.

5. Wound data and munitions effectiveness team database. Bethesda, MD, USA: Casualty Care Research Center, Department of Military and Emergency Medicine, Uniformed Services University; 2004.

6. Viano DC, Lau IV. Thoracic impact: a viscous tolerance criterion. In: Tenth International Conference on Experimental Safety Vehicles, Oxford, UK. Washington, DC, USA: U.S. Government Printing Office; 1985. p. 104-14.

7. Sturdivan LM, Viano DC, Champion H. Analysis of injury criteria to assess 
chest and abdominal injury risks in blunt and ballistic impacts. J Trauma. 2004;56(3):651-63.

8. Rice K, Lightsey S. An update on U.S. National Institute of Justice performance standards for personal body armor. In: Proceedings from the 5th Personal Armor Safety Symposium. Colchester, UK; International Personal Armour Committee; 2000. p. 235-44.

9. Office of Law Enforcement Standards (OLES) of the National Institute of Standards and Technology (NIST). Ballistic Resistance of Personal Body Armor (NIJ Standard No. 0101.04). Washington, DC, USA: Office of Science and Technology, National Institute of Justice (NIJ), U.S. Department of Justice; 2001.

10. Clare VR, Lewis JH, Mickiewicz AP, Sturdivan LM. Projectile induced blunt trauma. In: Sturdivan LM, Clare VR, editors. Handbook of human vulnerability criteria. Edgewood Arsenal, MD, USA: Edgewood Arsenal Publications; 1975. p. 1-12.
11. Association for the Advancement of Automotive Medicine (AAAM). The abbreviated injury scale. 1998 revision. Des Plaines, IL, USA; AAAM; 1998.

12. Kent R, Bass C, Woods W, Sherwood C, Madeley NJ, Salzar R, Kitagawa Y. Muscle tetanus and loading condition effects on the elastic and viscous characteristics of the thorax. Traffic Inj Prev. 2003;4:297-314.

13. Lewis EA, Johnson CP, Bleetman A, Bir CA, Horsfall I, Watson C, et al. An investigation to confirm the existence of "pencilling" as a non-penetrating behind armour injury. In: van Bree JLMJ, editor. Proceedings from the 7th Personal Armor Safety Symposium. Den Haag, The Netherlands; TNO Prins Maurits Laboratory; 2004.

14. Bir C. The evaluation of blunt ballistic impacts of the thorax [doctoral dissertation]. Detroit, MI, USA: Wayne State University; 2000. 